\title{
Martín Fierro. Una mirada del hombre del siglo XIX desde su lugar de desterrado
}

\author{
Milagros Rojo Guinazú Chiozzi
}

UNNE

\section{Resumen}

José Hernández, con su personaje y obra Martín Fierro, nos acerca a una mirada posible del desterrado en periodos de reorganización nacional. La misma es atravesada por el enfoque político que el autor asume tanto en La Ida como en La Vuelta.

El gaucho Martín Fierro - un excluido social- debe adaptarse o huir. Sufre una pena que el Estado le impone por cometer el delito de "no pertenecer", de no cumplir con ninguno de los estándares requeridos para constituirse como ciudadano libre y con derechos. Es expulsado de su territorio, de su vida, de su idiosincrasia; estableciéndose un correlato con la muerte civil del ser humano.

De acuerdo con el enfoque teórico propuesto por Lucila Pagliai (2005:127-128) "La cuestión de la frontera y el desierto, del lugar del gaucho en el nuevo orden, de la pampa gringa y el alambrado son temas de alta conflictividad social que ingresan en la literatura de diversos modos, y alrededor de los cuales se van organizando en la cultura argentina dos campos de gran dinamismo, fluidez y continuidad: el de la tradición y el del progreso."

Los lectores nos encontramos frente a una mirada desde el exilio de un personaje, que nos obliga a indagar respecto del paradigma ideológico que subyace tras cada una de sus palabras. El gaucho debe ser despojado de ese signo negativo que conlleva su particular denominación; Josefina Ludmer (1984: 472)alude a que "(...) La nueva lengua literaria señala su desmarginalización, su reconocimiento y mutación (...)"

Este trabajo pretende mostrar un posible recorrido tanto de lectura como de análisis de una obra literaria crucial para la cultura argentina, contextualizada en un periodo de construcción de la identidad nacional, la que se edifica desde la perspectiva de un desterrado.

Palabras Clave:

Desterrado, reorganización nacional, gaucho, obra literaria, civilización, barbarie, ideología

\section{Martín Fierro. Una mirada del hombre del siglo XIX desde su lugar de desterrado}

Detener la mirada en el ser argentino que habita las pampas en el siglo XIX, nos conduce al encuentro con Martín Fierro, poema épico narrativo que define a una clase y a una nación. Asimismo, escoger el lugar del desterrado como focalización de análisis requiere la mención e indagación de aspectos inherentes al personaje y a su autor.

José Hernández, con su personaje y obra Martín Fierro, nos acerca a una mirada del desterrado en períodos de reorganización nacional. La misma está atravesada por la orientación política que el escritor asume tanto en La Ida como en La Vuelta.

Si consideramos los orígenes de ambas partes, convendremos recordar que desde 1868 Hernández se caracterizó por la emisión de mensajes pacifistas que abogaban por el cese -por 
parte del gobierno- de la guerra con Paraguay; asimismo; buscaba que se derogara la inconstitucional ley de fronteras, la que obligaba a prestar servicios en las mismas y que traía consigo la persecución y exterminio del gaucho. A partir de esto, se devela la creación de Martín Fierro, La Ida.

Podemos identificar una clara contradicción entre el accionar político de Hernández y su posicionamiento como autor de la obra. Esto se desprende de la evidencia que se define en el texto literario cuando destaca las deficiencias y calvarios que sufre el sector marginal de la sociedad a la que pertenece Martín Fierro por parte del Estado, aunque luego esboce las reformas necesarias para que éste desaparezca en beneficio de la modernización, del progreso material del país y la Nación en formación.

Estas coyunturas coinciden con la publicación de La vuelta de Martín Fierro (1879), periodo que se caracteriza, entre otras cuestiones, por la llegada de los inmigrantes extranjeros al Río de la Plata, el ferrocarril, así como por la unificación y afianzamiento del Estado. Desde ciertas líneas de pensamiento, la "desaparición del gaucho" como sujeto histórico real podría significar su resurgimiento como sujeto mítico-literario y como el prototipo del "ser nacional" criollo.

Tomando este primer aspecto coyuntural implícito en la obra, analizaremos dos fragmentos:

Aquí me pongo a cantar / al compás de la viguela, / que el hombre que lo desvela / una pena estraordinaria, / como la ave solitaria, /con el cantar se consuela. (...)/ Mas ande otro criollo pasa /Martín Fierro ha de pasar; /nada lo. hace recular/ ni los fantasmas lo espantan; /y ende que todos cantan /yo también quiero cantar. Cantando me he de morir, /cantando me han de enterrar, /y cantando he de llegar /al pie del Eterno Padre: / Dende el vientre de mi madre /vine a este mundo a cantar. (...) /. Soy gaucho, y entiéndalo /como mi lengua lo esplica: /Para mi la tierra es chica /y pudiera ser mayor; /ni la víbora me pica /ni quema mi frente el sol. (...)/ Mi gloria es vivir tan libre /como el pájaro del cielo; /no hago nido en este suelo, /ande hay tanto que sufrir, / y naides me ha de seguir /cuando yo recuento el vuelo. (...)/ Y entiendan la relación /que hace un gaucho perseguido, /que padre y marido ha sido /empeñoso y diligente, / y sin embargo la gente /o tiene por un bandido. (Hernández, 1982:132-140)

En este primer ejemplo se registra la mirada de un hombre que expone, defiende e impregna con su ideología de vida ese aire o perfil que lo define. Esa categoria de bandido, delincuente, malviviente, vago, entre otras inferencias que se puedan hacer; nos permite establecer una suerte de posicionamiento de la persona frente al contexto en el que vive y con respecto a ese progreso que prospera e intenta perturbar la serenidad de su universo.

Atención pido al silencio /y silencio a la atención, / que voy en esta ocasión /si me ayuda la memoria, /a mostrarles que a mi historia /le faltaba lo mejor. (...)/ El campo es del inorante, /el pueblo, del hombre estruido; /yo que en el campo he nacido, /digo que mis cantos son, /para los unos... sonidos, /y para los otros... intención. (...) / Brotan quejas de mi pecho, /brota un lamento sentido; /y es tanto 
lo que he sufrido, /y males de tal tamaño, /que reto a todos los años /a que traigan el olvido. (...) / Aunque rompí el estrumento /por no volverme a tentar, /tengo tanto que contar/y cosas de tal calibre, /que Dios quiera que se libre /el que me enseñó a templar. (...). (Hernández, 1982: 213- 217)

En este segundo ejemplo, la focalización del personaje se modifica. Se transparenta la intención del autor de manifestar esa búsqueda de la unión y consolidación del Estado. Ese espíritu indómito del gaucho se apacigua, se distiende; como si la representación de este sujeto como gaucho se desvaneciera, para dar cabida al criollo, al modelo de hombre nacional. Tal como lo expresa Josefina Ludmer (2000:27). “(...) En la rueda de La Vuelta los dos enemigos y padres de la patria, el de la ley y el de la educación, son lo mismo: en la voz del gaucho educación es igual a ley. (...)"

Sin lugar a dudas, se puede descubrir en el discurso de Hernández un posicionamiento ideológico personal. Por intermedio de la figura medular de Fierro, y de los sucesos protagonizados por el mismo, el paradigma cambia. Ya no se defiende al gaucho como sujeto social, con derechos y distintivos propios; sino que se lo incorpora en un proceso de reorganización nacional.

Podemos reconocer, como elemento causal al que inscribe el autor, a una ruptura de secuencias sociales lógicas; las que se exhiben como fundamento o razón que promueve un comportamiento disonante en el protagonista con respecto a la sociedad en la que vive. Así, el autor se posiciona en una focalización que toma como auténtica y desde donde argumenta tanto la agresividad de Martín Fierro como su actitud combativa. Desde esta perspectiva, el personaje de Hernández señala y reprueba a un sistema, tal como queda inscripto en la obra.

En el Canto XII de La Ida es posible identificar con claridad esta perspectiva de análisis:

(...) Nace el gaucho, y se hace viejo /sin que mejore su suerte, /hasta que por ahi la muerte /sale a cobrarle el pellejo. (...) Andaremos de matreros /si es preciso pa salvar. /Nunca nos ha de faltar /ni un guen pingo pa juir, /ni un pajal ande dormir, /ni un matambre que ensartar. (...) Todo se guelven proyectos /de colonias y carriles, /y tirar la plata a miles /en los gringos enganchaos, /mientras el pobre soldao /le pelan la chaucha jah viles! (...) Hace mucho que sufrimos /la suerte reculativa. /Trabaja el gaucho y no arriba, /pues a lo mejor del caso/lo levantan de un sogaso /sin dejarle ni saliva. (...) Y se hacen los que nos aciertan /a dar con la coyuntura: /Mientras el gaucho lo apura /con rigor la autoridá, /ellos a la enfermedá /le están errando la cura. (Hernández, 1982: 196-199)

La mirada del condenado se configura como parte integral de su inexorable destino, de un determinismo al que no puede evitar. Podrá huir, aseverando su cualidad de desterrado; o aceptar el sometimiento que le impone la autoridad, transformándose en un subordinado, en un esclavo.

En la primera parte de la obra se puede vislumbrar esa voluntad preliminar del gaucho de intentar adaptarse a la realidad histórica del país. La condición específica del gaucho se sostiene, dada su naturaleza fatalista, en el proverbio de "dejar hacer y dejar pasar" sin 
inmiscuirse ni oponer resistencia. De esta manera, en el canto III es posible identificar un ejemplo de su moderación natural:

(...) Cantando estaba una vez / En una gran diversión, / Y aprovechó la ocasión / Como quiso el Juez de Paz... / Se presentó y ahí nomás / Hizo una arriada en montón. (...)(Hernández, 1982: 146)

La autoridad implacable encarna al gobierno de Sarmiento. El autor lo realiza a través del Juez de Paz que simboliza y corporiza a ese mando. Es éste el que irrumpe el lugar esencial y sacro del gaucho para provocar una voluntad inaudita, para sus costumbres culturales y para las inquietudes de su vida. De este modo, la obra se traslada hacia la reflexión expresa y calificativa del concepto de libertad que define al gaucho, tal como lo podemos evidenciar en el Canto VIII de La Ida:

(...) Monté y me encomendé a Dios, /rumbiando para otro pago; /que el gaucho que llaman vago /no puede tener querencia, /y ansí, de estrago en estrago, /vive yorando la ausencia. / $\mathrm{El}$ anda siempre juyendo. /Siempre pobre y perseguido; /no tiene cueva ni nido, /como si juera maldito; /porque el ser gaucho... ¡barajo!, /El ser gaucho es un delito. (...) Su casa es el pajonal, /su guarida es el desierto; /y si de hambre medio muerto /e echa el lazo a algún mamón, /o persiguen como a plaito /porque es un gaucho ladrón. (...) (Hernández, 1982: 174-177)

El gaucho Martín Fierro -un excluido social- debe adaptarse o huir. Sufre una pena que el Estado le impone por cometer el delito de "no pertenecer", de no cumplir con ninguno de los estándares requeridos para constituirse como ciudadano libre y con derechos. Es expulsado de su territorio, de su vida, de su idiosincrasia; estableciéndose un correlato con la muerte civil del ser humano.

Se institucionaliza, a partir del protagonista, el modelo de víctima; pues él es portador de la memoria colectiva que condensa las regulaciones convencionales impuestas o propuestas por la sociedad. Precisamente, las concepciones que él formula representan una verbalización simbólica de la historia, a la que el autor pretende juzgar y describir desde la esencia cultural del gaucho.

Así lo podemos reconocer en el canto 27 cuando Picardía relata las particulares condiciones de la vida en la frontera; en donde los gauchos son obligados a trabajar y a sacrificarse incesantemente sin recibir pago alguno. Asimismo, tienen que acatar sin miramientos a sus superiores pues su insubordinación se pagaba con feroces sanciones. En definitiva, nos confiesa cómo el gaucho se debatía entre tres opciones: tolerar la terrible situación en la que se encontraba, desertar y convertirse en un renegado, o ser asesinado.

Igualmente, en la obra es factible identificar a los gauchos que se deja en libertad para que retornen a sus hogares. No obstante, esta posibilidad únicamente simboliza el regreso a un territorio despoblado, vacío. Por esto, no tienen otra alternativa que transformarse en matreros.

En sus versos Picardía responsabiliza a la Providencia; sin embargo, reconocemos que son las autoridades (ley, justicia y gobierno) las culpables de esa situación, porque no sólo no se 
preocupan por la integridad y bienaventuranza de los gauchos, sino que se benefician de ellos cuanto pueden $y$, para conseguirlo, son descomunalmente inflexibles.

La manifiesta voluntad de Hernández se desprende de la obra tanto por su esfuerzo como por su búsqueda de la igualdad para el gaucho en ese contexto social. Así, forja la vida de su protagonista pretendiendo acentuar ese derecho inalienable a la autorrealización humana.

(...) Y aunque yo por mi inorancia /con gran trabajo me esplico, /cuando llego a abrir el pico, /ténganlo por cosa cierta: /sale un verso y en la puerta /ya asoma el otro al hocico. /Y emprésteme su atención, /me oirá relatar las penas /de que traiga la alma llena, /porque en toda circunstancia /paga el gaucho su inorancia /con la sangre de las venas. (...)/ Monté y me largué a los campos /más libre que el pensamiento, /como las nubes al viento, /a vivir sin paradero; /que no tiene el que es matrero /nido, ni rancho, ni asiento. (...) (Hernández, 1982: 192-195)

De acuerdo con el enfoque teórico propuesto por Lucila Pagliai(2005:127-128 "La cuestión de la frontera y el desierto, del lugar del gaucho en el nuevo orden, de la pampa gringa y el alambrado son temas de alta conflictividad social que ingresan en la literatura de diversos modos, y alrededor de los cuales se van organizando en la cultura argentina dos campos de gran dinamismo, fluidez y continuidad: el de la tradición y el del progreso.").

Hernández consideraba, tal como lo expresa en la Carta a los editores de la octava edición de La Ida en 1874, que el hijo de los campos seguiría siendo una agente indispensable para la industria rural en tanto y en cuanto la ganadería constituyera una de las principales fuentes de riqueza pública. Por esto, abogaba por su carácter de ciudadano, con deberes y derechos; así como por la consideración referente a que su cultura debía ser la fuente de su mejora.

De acuerdo con el posicionamiento ideológico de Sarmiento, esa urgencia o necesidad del gaucho de "forjarse un mundo con su moral y sus leyes aparte", deriva de esa vida errática y pendenciera que caracteriza a esta clase.

Martín Fierro se reconoce excluido por el sistema, pues no estar en una lista significaba la marginación a los derechos otorgados a aquellos hombres que la componen. Referimos a la ley arbitraria del ninguneo que define a los gobiernos totalitarios.

A lo largo de la obra se evidencia esta realidad, dado que ese mecanismo del sistema vigente que rige la legalidad de las listas de paga ha determinado al gaucho a un destino errático que lo constrenirá a una conducta pendenciera.

Desde este punto vista, podemos aludir al determinismo darwiniano de herencia y ambiente que se legitimara en esos tiempos. Así lo expone Sarmiento cuando despliega sus disquisiciones cientificas referentes a la barbarie.

Como lectores nos encontramos frente a una contemplación desde el exilio de un personaje, que nos obliga a indagar respecto del paradigma ideológico que subyace tras cada una de sus palabras.

El gaucho debe ser despojado de ese signo negativo que conlleva su particular denominación; Josefina Ludmer alude a que "(...) La nueva lengua literaria señala su desmarginalización, su reconocimiento y mutación (....)" (Ludmer, 2000: 472). 
En el Canto II de La Ida descubrimos ese estado del hombre cuando expresa: “(...) que gasta el pobre la vida len juir de la autoridá. (...) / Ahi comienzan sus desgracias, lahi principia el pericón; /porque ya no hay salvación, /y que usted quiera o no quiera, /lo mandan a la frontera /o lo echan a un batallón. (...)" (Hernández, 1982: 144).

No es fortuita la línea política que circunscribe a $L a I d a$, durante la presidencia de Sarmiento, y a La Vuelta, durante la presidencia de Avellaneda, esta última coincidente con la postura ideológica del autor. De este modo, en La ida canta: “(...) A mi el juez me tomó entre ojos / en la última votación: / me le habia hecho el remolón ly no me arrimé ese día, ly él me dijo que yo servía /a los de la exposición. (...) /Al principio nos dejaron /de haraganes, criando sebo, /pero después... no me atrevo la decir lo que pasaba... / iBarajo! Si nos trataban /como se trata a malevos. (...)/ Más de un año nos tuvieron len esos trabajos duros (...)" (Hernández, 1982: 145 - 154). Por el contrario, en La Vuelta su canto tiene otro tenor: "(...) Vive el águila en su nido, lel tigre vive en la selva, /el zorro en la cueva agena, $/ y$, en su destino incostante, /sólo el gaucho vive errante /donde la suerte lo lleva. / Es el pobre en su orfandá /de la fortuna el desecho, /porque naides toma a pechos /el defender a su raza. /Debe el gaucho tener casa, lescuela, iglesia y derechos. (...)" (Hernández, 1982: 357 - 360).

Con ambos ejemplos visualizamos la alteración en cuanto al punto de vista, no sólo del autor, sino de su personaje que racionaliza lo instituido como condición necesaria para su permanencia en ese contexto.

En conclusión, con esta presentación se intentó mostrar un posible recorrido, tanto de lectura como de análisis de una obra literaria crucial para la cultura argentina como es Martín Fierro. La misma, contextualizada en un período de construcción de la identidad nacional, nos permite proyectar una perspectiva del destierro, la mirada y reflexión del gaucho como clase desarraigada, despojada de su condición y naturaleza esencial.

\section{Referencias}

HALPERÍN DONGHI, Tulio (2006) José Hernández y sus mundos. Sudamericana: Bs. As. HERNÁNDEZ, José (1982) Martín Fierro. Hyspamérica: Buenos Aires.

LUDMER, Josefina (2000) El género gauchesco. Un tratado sobre la patria. Perfil: Bs. As. MIGUEZ, Eduardo (2005) El mundo de Martín Fierro. Eudeba: Buenos Aires.

PAGLIAI, Lucila (2005) Manual de literatura argentina (1830-1930). Universidad Nacional de Quilmes: Buenos Aires.

TORRES DE PERALTA, Elba (1989) El gaucho Martín Fierro. Ruptura de secuencias sociales lógicas. AIH, Actas X. California State University, Los Ángeles.

Milagros Rojo Guinaazú Chiozzi es Profesora y Licenciada en Letras, Especialista en Docencia Universitaria. Egresada de la Universidad Nacional del Nordeste (UNNE). Docente de la Facultad de Humanidades (UNNE). Miembro Asociado de la Asociación Argentina de Literaturas Comparadas $(A A L C)$. Ha presentado y publicado trabajos referentes a las áreas de: Literatura Francesa, Literatura Argentina y Comunicación. 